\title{
"A study to identify the discomforts as verbalized by patients during the post operative period of CABG surgery, admitted in K.L.E.S's hospital, Belgaum".
}

\author{
Shalmon $\mathrm{SC}^{1}$ \\ (Department of Nursing, BLDEA's Shri BM Patil institute of Nursing science, Bijapur/ Rajiv Gandhi university \\ of Health sciences, India)
}

\begin{abstract}
The study determines the discomfort as verbalized by patients during the post operative period of $C A B G$ surgery. Tools used for assessment are Socio-demographic data of the patient and structured questionnaire to assess the level of discomfort. Sample of the study comprised of 60 post operative surgery patients admitted in K.L.E.S's hospital, Belgaum. Scrutinizes revealed that on $1^{\text {st }}$ postoperative day, 58 (98\%) subjects had discomfort in relation to catheters, 34 (56\%) of subjects had discomforts related to temperature, $26(43.33 \%)$ had discomforts due to noise.
\end{abstract}

Keywords: CABG Surgery, Discomfort, Post operative period, Socio-demographic data.

\section{Introduction}

The study summarizes the discomfort as verbalized by patients during the post operative period. During illness and hospitalization patients are subjected to situations and circumstances that cause discomfort. In fact the incidence of disease and the necessity for hospital admission are the major factors of physiological and psychological distress. Fear, anxiety, denial, depression and responses to physical illness are a real source of discomfort. For the patient, decision to undergo surgery stands as a moment of crisis in life. Regardless of its purpose, a surgery is always a stressful for the patient. Uncertainly as to the outcome of the operation, fear of changed body image, fear of anesthesia are some of the factors adding to the physical stress of the patient ${ }^{1}$. So meeting the comfort needs is an integral part of nursing care. More than any other member of the health team it is the nurse who plays important role in promoting comfort for patients in all situations.

\section{Headings}

Comfort is a complex construct in which nurses claim a disciplinary interest. The structure of comfort is complex because it entails a multidimensional, personal experience with differing degrees of intensity ${ }^{2}$. The history of comfort as a Nursing Diagnosis reveals the definitional difficulties associated with this complex construct. In the classification scheme developed by the North American Nursing Diagnosis Association (NANDA) diagnoses are based on patient's needs or deficits ${ }^{3,4}$. A nurse is judged always by her ability to make her patient comfortable. Comfort is both physical and mental, and nurses responsibility does not end with physical care" Skill full nurse is always judged by her ability to make her patient comfortable. There is no doubt that nurses in cardiac care units demonstrate greater skill in handling equipment and monitoring patients than in earlier times. But we cannot ignore the fact that the patient's individual needs have to be identified and take care of if we believe in good patient care ${ }^{5}$.

\section{Indentations And Equations}

The conceptual framework for this present study was based on the Katherine Kolcaba's Theory of Comfort. The sample of the study comprised of 60 post operative CABG surgery patients, admitted in intensive thoracic unit, K.L.E.S's Hospital and Medical Research Centre, Belgaum. Purposive sampling technique was used to draw the sample for the research study. The tools developed and used for the data collection were Sociodemographic data of the post operative CABG surgery patients, on six postoperative CABG surgery patients by structured interviews schedule. Five experts validated the content of the tool and it was found to be reliable and feasible. The reliability of the tools was established by Spearman's Brown Prophecy Formula it was found reliable and the calculated value is 0.99 . The pilot study was conducted as a part of major study. Tools proved to be comprehensive, feasible and acceptable. The main study (data collection) was conducted from $15^{\text {th }}$ January 2003 to $15^{\text {th }}$ February 2003, after obtaining permission from the concerned authorities, rapport was developed with the sister in charge and the staff of the ITCU, Cardiac private and general ward.. Every day the investigator visited the patient's pre-operatively in order to develop rapport with them, so that post-operatively the selected patients would respond adequately in an atmosphere of familiarity and trust. The data collected by structured interview schedule method and the collected data was analyzed. The data gathered were analyzed and 
interpreted according to the objectives. Descriptive statistics used were frequency, percentage, mean, percentage score, and standard deviation. Further inferential statistics like Paired t-test was used to test the hypothesis at $\mathrm{p}<$ 0.05 level of significance and the data obtained are presented in the graphical form.

The data has been organized and analyzed under the following headings:

1) Socio-demographic data in relation to age, gender, educational status, habitat, occupation and marital status.

2) Distribution of subjects according to the physical discomfort on $1^{\text {st }}$ and $3^{\text {rd }}$ postoperative discomfort.

3) Distribution of subjects according to the physiological discomfort on $1^{\text {st }}$ and $3^{\text {rd }}$ postoperative discomfort.

4) Distribution of subjects according to the psychological discomfort on $1^{\text {st }}$ and $3^{\text {rd }}$ postoperative discomfort.

5) Mean, SD, Mean difference and paired't' value of the physical, physiological and psychological discomfort of the $1^{\text {st }}$ and $3^{\text {rd }}$ postoperative discomfort.

The above headings are described in the figures and tables section.

\section{Figures And Tables}

\section{Table 1:}

Distribution of subjects by socio-demographic variable

\begin{tabular}{|l|c|c|c|c|}
\hline \multirow{2}{*}{ Discomfort related to areas } & \multicolumn{2}{|c|}{$\mathbf{1}^{\text {st }}$ POD } & \multicolumn{2}{c|}{$\mathbf{3}^{\text {rd }}$ POD } \\
\cline { 2 - 5 } & Mean & $\mathbf{\%}$ & Mean & \multicolumn{1}{c|}{} \\
\hline Bed & 21 & 35.35 & 5 & 8.33 \\
\hline Catheters (Chest tubes / SRC) & 58 & 98 & 17 & 28.33 \\
\hline Electronic appliances & 17 & 28.33 & 0 & 0 \\
\hline Noise & 26 & 43.33 & 16 & 26.33 \\
\hline Temperature & 34 & 56 & 0 & 0 \\
\hline Light & 17 & 28.33 & 4 & 6.66 \\
\hline Any other environmental factors & 11 & 18.33 & 13 & 21.66 \\
\hline
\end{tabular}

$\mathbf{N}=60$

Table 2:

Distribution of physical discomforts on the $1^{\text {st }}$ day and $3^{\text {rd }}$ post-operative day (POD)

\begin{tabular}{|c|c|c|}
\hline Sample Characteristics & Frequency & $\%$ \\
\hline \multicolumn{3}{|l|}{ A. Gender } \\
\hline - $\quad$ Male & 52 & 86.66 \\
\hline - $\quad$ Female & 8 & 13.33 \\
\hline \multicolumn{3}{|l|}{ B. Age (in years) } \\
\hline - $\quad 40-49$ & 10 & 16.66 \\
\hline - $\quad 50-59$ & 23 & 38.33 \\
\hline - 60 and above & 23 & 45 \\
\hline \multicolumn{3}{|l|}{ C. Educational Status } \\
\hline - $\quad$ Post Graduate & 5 & 8.33 \\
\hline - $\quad$ Graduate & 13 & 21.66 \\
\hline - Higher Secondary & 16 & 26.66 \\
\hline - Secondary & 11 & 18.33 \\
\hline - $\quad$ Primary & 14 & 23.33 \\
\hline - No Formal & 1 & 1.66 \\
\hline \multicolumn{3}{|l|}{ D. Habitat } \\
\hline - $\quad$ Rural & 7 & 11.66 \\
\hline - $\quad$ Semi Urban & 29 & 48.33 \\
\hline - Urban & 24 & 40 \\
\hline \multicolumn{3}{|l|}{ E. Occupation } \\
\hline $\begin{array}{ll}\text { - } & \text { Skilled } \\
\end{array}$ & 7 & 11.66 \\
\hline - $\quad$ Semiskilled & 42 & 70 \\
\hline - Unskilled & 6 & 10 \\
\hline - $\quad$ Retired & 5 & 8.33 \\
\hline \multicolumn{3}{|l|}{ F. Marital status } \\
\hline $\begin{array}{ll}- & \text { Married } \\
\text { - } & \text { Single }\end{array}$ & $\begin{array}{c}59 \\
1\end{array}$ & $\begin{array}{c}98.33 \\
1.66\end{array}$ \\
\hline
\end{tabular}




\section{Figure 1:}

Distribution of physical discomforts on $1^{\text {st }}$ And $3^{\text {rd }}$ post-operative day (POD)

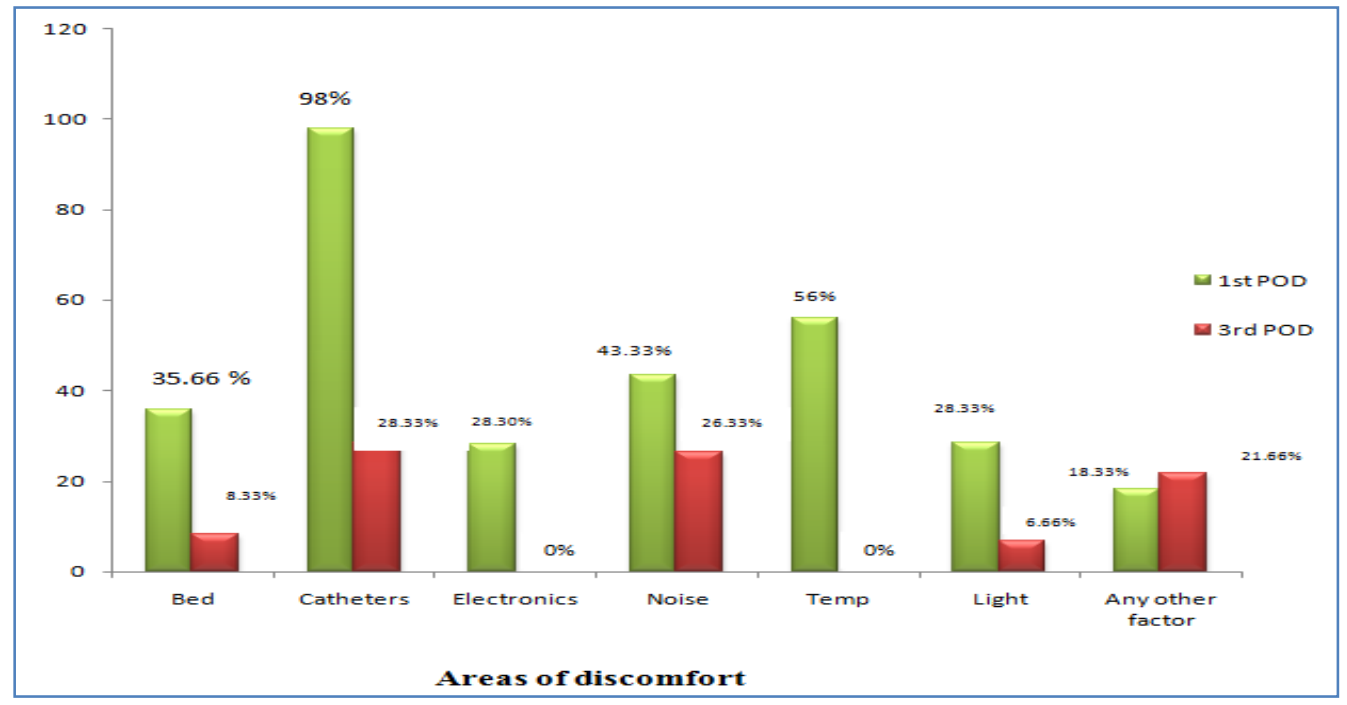

Table 3:

Distribution of physiological discomfort on $1^{\text {st }}$ and $3^{\text {rd }}$ post-operative day (POD)

\begin{tabular}{|c|c|c|c|c|}
\hline \multirow[t]{2}{*}{ Discomfort related to areas } & \multicolumn{2}{|c|}{$\mathbf{1}^{\text {st }}$ POD } & \multicolumn{2}{|c|}{$3^{\text {rd }}$ POD } \\
\hline & Frequency & $\%$ & Frequency & $\%$ \\
\hline Sleep & 57 & 95 & 6 & 10 \\
\hline Pain & 60 & 100 & 43 & 71.66 \\
\hline Difficulty in taking food & 21 & 35 & 9 & 15 \\
\hline Dressing & 59 & 98.33 & 29 & 48.33 \\
\hline Chest physiotherapy & 25 & 41.66 & 7 & 11.66 \\
\hline Urinal / bedpan & 34 & 56.66 & 6 & 10 \\
\hline Ambulation & 22 & 36.66 & 53 & 86.66 \\
\hline Tolerance of food & 4 & 6.66 & 5 & 8.33 \\
\hline Difficulty in using toilet & 2 & 3.33 & 18 & 30 \\
\hline Activities making tired & 46 & 76.66 & 32 & 53.33 \\
\hline Breathlessness, increased HR & 15 & 25 & 6 & 10 \\
\hline Abdominal discomfort & 3 & 15 & 20 & 33.33 \\
\hline
\end{tabular}

Figure 2:

Distribution of physiological discomfort on $1^{\text {st }}$ and $3^{\text {rd }}$ post-operative day (POD)

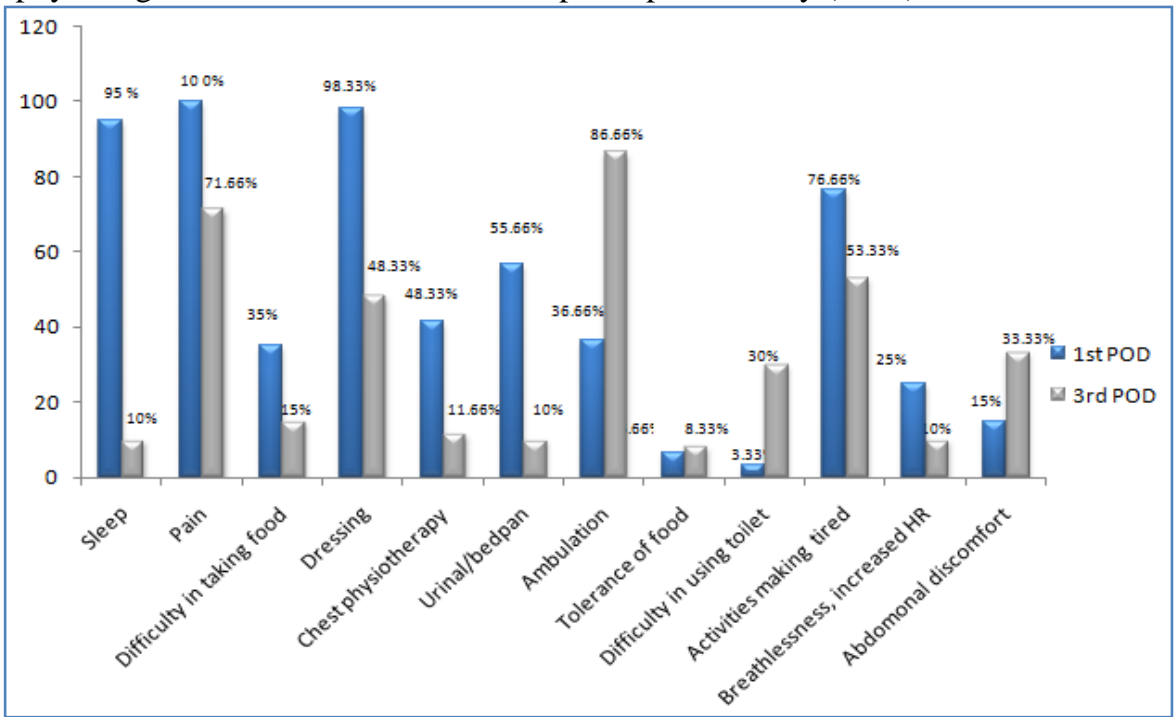


Table 4:

Distribution of psychological discomfort on $1^{\text {st }}$ and $3^{\text {rd }}$ post-operative day (POD)

\begin{tabular}{|c|c|c|c|c|}
\hline \multirow[t]{2}{*}{ Discomfort related to areas } & \multicolumn{2}{|c|}{$1^{\text {st }}$ POD } & \multicolumn{2}{|c|}{$3^{\text {rd }}$ POD } \\
\hline & Frequency & $\%$ & Frequency & $\%$ \\
\hline Anxiety & 26 & 43.33 & 11 & 18.33 \\
\hline Nervousness & 22 & 36 & 10 & 16.66 \\
\hline Tension & 31 & 51.66 & 6 & 10 \\
\hline Unhappiness / Uneasiness & 34 & 56.66 & 15 & 25 \\
\hline Fear related to finance & 17 & 28.33 & 13 & 21.66 \\
\hline Fear related to future & 24 & 40 & 10 & 16.66 \\
\hline Unmet information & 20 & 33.33 & 12 & 20 \\
\hline Cry & 10 & 30 & 13 & 21.66 \\
\hline
\end{tabular}

Figure 3:

Distribution of psychological discomfort on $1^{\text {st }}$ and $3^{\text {rd }}$ post-operative day (POD)

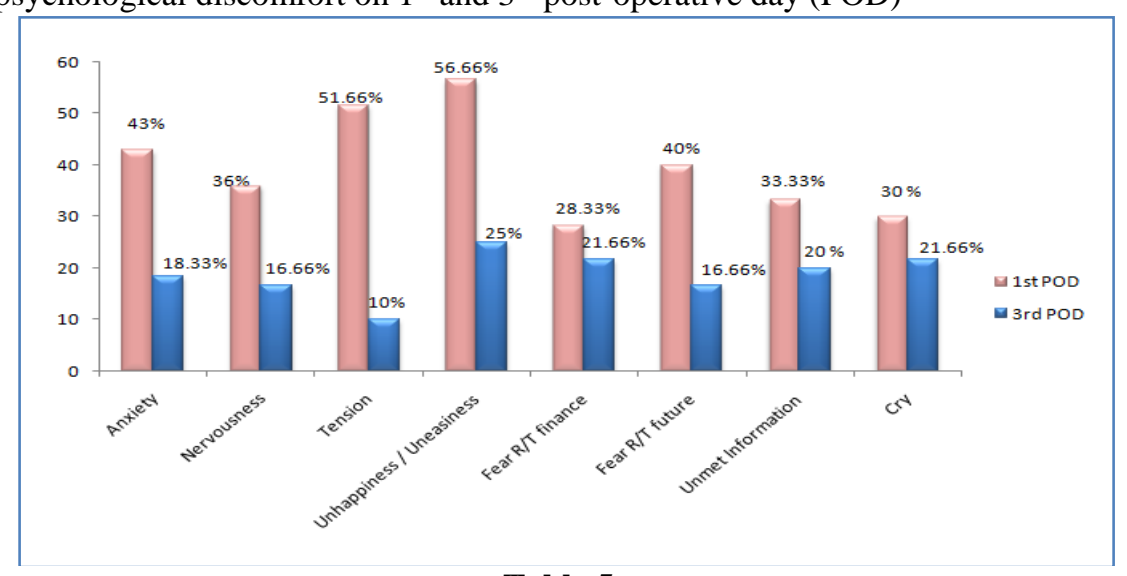

Table 5:

Mean difference of the physical, physiological and psychological discomforts of $1^{\text {st }}$ and $3^{\text {rd }}$ POD

\begin{tabular}{|c|c|c|c|c|c|c|c|c|}
\hline \multirow[t]{2}{*}{ Discomforts } & \multicolumn{2}{|c|}{$\mathbf{1}^{\text {st }}$ POD } & \multicolumn{2}{|c|}{$3^{\text {rd }}$ POD } & \multicolumn{2}{|c|}{ Difference } & \multirow{2}{*}{$\begin{array}{l}\text { Paired 't' } \\
\text { value }\end{array}$} & \multirow{2}{*}{$\mathbf{P}$} \\
\hline & Mean & SD & Mean & SD & Mean & SD & & \\
\hline Physical & 3.06 & 1.27 & 0.91 & 0.99 & 2.16 & 1.24 & 13.012 & .000000 \\
\hline Physiological & 5.8 & 1.62 & 3.88 & 1.36 & 1.91 & 1.96 & 7.518 & .000000 \\
\hline
\end{tabular}

Figure 4:

Mean difference of the physical, physiological and psychological discomforts of $1^{\text {st }}$ and $3^{\text {rd }}$ POD

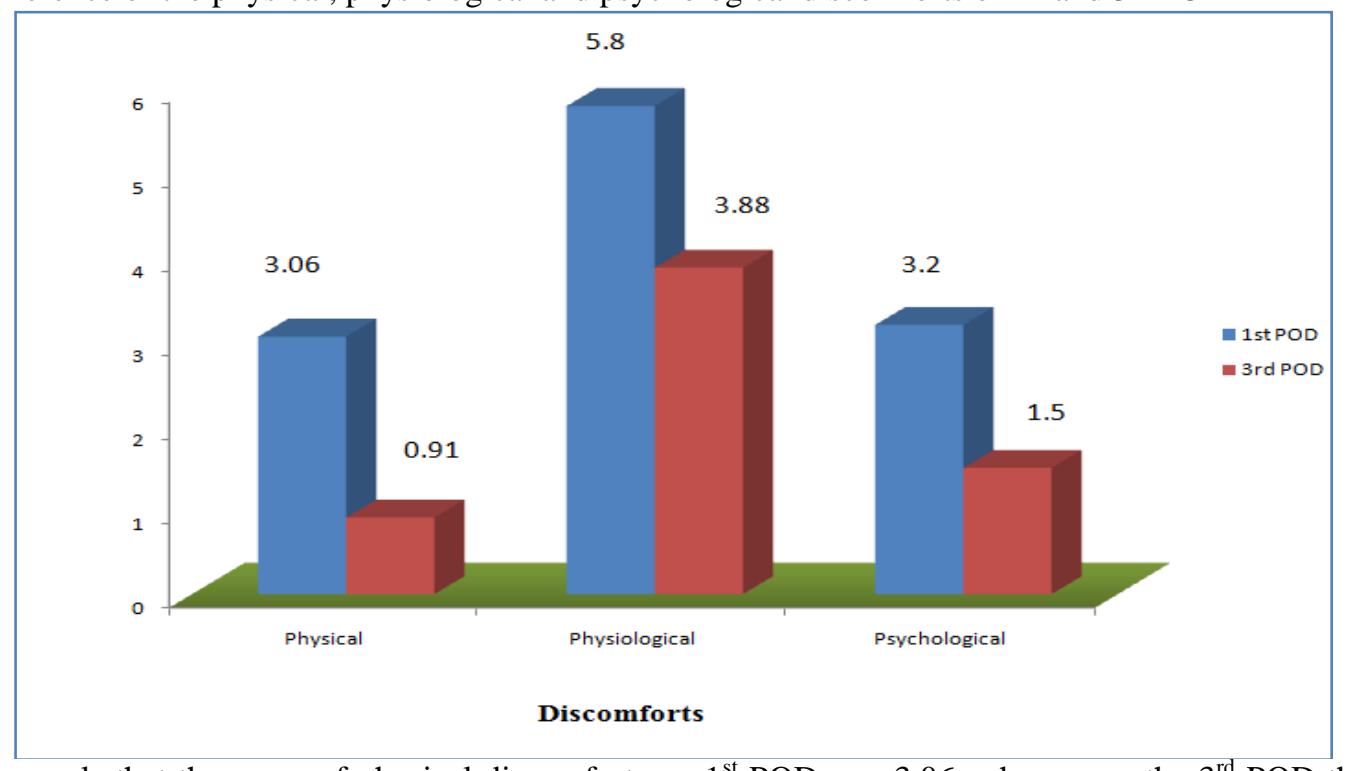

Table 5 reveals that the mean of physical discomforts on $1^{\text {st }}$ POD was 3.06 , whereas on the $3^{\text {rd }}$ POD the mean score was 0.91 with a mean difference of 2.16 and the computed paired ' $t$ ' value was found 13.012 , which was statistically significant at $0.000000(<0.001)$ level. 
Regarding the physiological discomforts, the mean score of physiological discomforts on $1^{\text {st }}$ POD was 5.8 , whereas on the $3^{\text {rd }}$ POD the mean score was 3.88 with a mean difference of 1.91 and the computed paired ' $t$ ' value was found 7.518 which was statistically significant at $0.000000(<0.001)$ level.

Mean score of psychological discomfort on $1^{\text {st }}$ POD was 3.2 , whereas on the $3^{\text {rd }}$ POD mean score of psychological discomfort was 1.5 with a mean difference of 1.63 and the computed paired ' $t$ ' value was found 10.121 which was statistically significant at $0.000000(<0.001)$ level.

\section{Conclusion}

From the present investigation following have been concluded:

1) Study showed that $1^{\text {st }}$ POD showed physiological discomforts were more than physical and psychological discomforts.

2) Study revealed that on $3^{\text {rd }}$ POD physiological discomforts existed more than physical and psychological discomforts.

3) According to study

- Physical discomforts in relation to catheter were high.

- In physiological discomforts, pain and sleep were more.

- In psychological discomforts uneasiness and anxiety were more.

\section{References}

[1]. Elhart.D, Scientific Principles In Nursing $8^{\text {th }}$ Edition (C.V.Mosby Co, Philadelphia, 1978).

[2]. K.Y. Kolcaba, An analysis of the concept of comfort. Journal of Advanced Nursing, 16, 1991, 1301-02

[3]. K.Y. Kolcaba, Holistic comfort: Operationalzing the construct as a nurse-sensitive outcome. Advances in Nursing Science, 15(1), 1992, 1-10.

[4]. K.Y. Kolcaba, Evolution of the mind range theory for outcomes research. Nursing Outlook, 49(2), 2001, 86-92.

[5]. Chuck, Vital Signs and Nurses Choices of titrated dosages of I/V morphine for relieving pain following cardiac surgery. Advanced Nursing Journal, 30(4), 858-65. 